\title{
UNA MIRADA SITUADA: APUNTES SOBRE LA CONFLICTIVIDAD AMBIENTAL LATINOAMERICANA Y EL CAMPO DEL DERECHO
}

\author{
QAWAYNINCHISMANTAPACHA: HAWA ABYA YALA \\ SASACHAKUYKUNA AMACHAYNIN
}

\section{A SITUATED LOOK: NOTES ON LATIN AMERICAN ENVIRONMENTAL CONFLICT AND THE FIELD OF LAW}

Ch'uyanchakuy: Kay ruwaypi, waqaykuna pachamamanchismanta latinoamericamamanta qawarisin, chay sikimanta, yuyarisun imapin derechuman yapamunman. Matrices economicas nisqawan qawarisun pachamamanchis awqaykunata derechukunata, imaynas kanman sapa hatun suyukunapi. Chayqa waqyasqa kashan, imaynatas yachapanku derechonisqapi. Ruwakunka chayqa lograkunqa huk objetivo crucial nisqata: paqarimuy kanqa chay awqaykunamanta latinoamerica nisqapi mecanismos de abordaje jurisdiccional nisqawan.

Yuyaysapa simikuna: Llapi, Pachamama, K'irinchay, Abya Yala, Kamachi

Resumen: En este trabajo se parte de identificar una tipología de conflictos ambientales compartidos por los países latinoamericanos y, sobre esa base, se busca reflexionar acerca del significado de ese dato para el campo del derecho. La conjunción entre las matrices económicas preponderantes en esos países y un acervo común de protección constitucional al ambiente nos permitirá identificar una tipología de conflictos ambientales jurídicamente relevantes, que tienen alta probabilidad de suceder en cada uno de ellos. Ese dato está llamado a incidir, sostendremos, en el diseño de nuestros sistemas jurídicos y en el modo en que éstos son estudiados y actuados dentro del campo del derecho. Al hacerlo se estará logrando un objetivo político crucial: gestar miradas situadas sobre la conflictividad latinoamericana y sus mecanismos de abordaje jurisdiccional.

(1) Abogado, Universidad Nacional de La Plata. Máster en Razonamiento Probatorio, Universidad de Girona. Especialista en Derecho Procesal, Universidad Notarial Argentina. Desempeña funciones en el Programa de Derechos Económicos, Sociales y Culturales de la Defensoría General de la Nación Argentina y como Secretario de Redacción en la Revista de Interés Público de la Facultad de Ciencias Jurídicas y Sociales de la Universidad Nacional de La Plata. Contacto: alejojgiles@gmail.com. 
Palabras clave: Desarrollo, Extractivismo, Ambiente, Latinoamérica, Derecho.

Abstract: In this paper we start by identifying a typology of environmental conflicts shared by Latin American countries and, on that basis, we seek to reflect on the meaning of this data for the field of law. The conjunction between the predominant economic matrices in those countries and a common acquis of constitutional protection to the environment will allow us to identify a typology of legally relevant environmental conflicts, which have a high probability of happening in each one of them. This data is called to influence in the design of our legal systems and in the way in which they are studied and acted within the field of law. In doing so, a crucial political objective will be achieved: gestating located views on Latin American conflict and its mechanisms of jurisdictional approach.

Keywords: Development, Extractivism, Environment, Latin America, Law. 


\section{Introducción}

Observamos América Latina. (2) Managua y Santiago; Quito y La Habana; Cochabamba y Potosí; La Quiaca y Guayaquil; Andalgalá y Belén; Cartagena y Montevideo. Esas y muchas otras ciudades cautivan nuestra atención. Estamos frente a una región extensa en territorio, heterogénea en su geografía y su clima, portadora de una diversidad ecológica de las más importantes del mundo.

Los países que la integran comparten muchas raíces. Una de ellas, fundamental, es la historia colonial que pesa sobre ellos: todos han sido colonias de países ubicados del otro lado del Atlántico, y luego de cruentas luchas se han independizado abriendo una etapa poscolonial que se encuentra en pleno desarrollo, siendo actualmente tensionada entre modelos antitéticos. ${ }^{(3)}$

Además de sus raíces históricas, estos países comparten muchos aspectos de su realidad contemporánea. (Lo cual está lejos de ser una casualidad, claro.) Entre ellos, uno interesará particularmente a este trabajo: el patrón común registrado en los modelos de desarrollo de los países de la región, los cuales están mayormente basados en el aprovechamiento de los recursos naturales.

La consolidación y profundización de esos modelos de desarrollo está generando una elevada y creciente presión sobre nuestros ecosistemas, con consecuencias devastadoras. Esos costos, ambientales, también traen asociados salientes costos sociales. Campesinos, indígenas, habitantes de las zonas aledañas a ciertas actividades productivas son las víctimas de ese modelo de desarrollo.(4) Sobre ellas se depositan los riesgos -desigualmente repartidos- de esos modelos de desarrollo, incompatibles con sus rasgos culturales y estilos de vida. ${ }^{(5)}$

Mientras tanto, el constitucionalismo latinoamericano ha ampliado los confines del campo del derecho consagrando un acervo normativo que -como veremos- condiciona esos patrones de desarrollo, tanto en los efectos que provocan como en los mecanismos de decisión sobre su rumbo. El funcionamiento

(2) Una primera aclaración terminológica: al referirse a América Latina este trabajo identificará al conjunto de países soberanos que comparten los siguientes criterios geográficos y lingüístico-culturales: los comprendidos entre México, al norte, y la Argentina, al sur, que tienen al español, al portugués o al francés como lenguas oficiales (mayoritarias). Ellos son: México, Guatemala, Honduras, El Salvador, Nicaragua, Costa Rica, Panamá, Cuba, Haití, República Dominicana, Colombia, Venezuela, Ecuador, Perú, Brasil, Bolivia, Paraguay, Chile, Uruguay y Argentina. Estos países integran -mas no completan- lo que algunos organismos internacionales (CEPAL, FAO, OMC, entre otros) denominan la región de América Latina y el Caribe (ALC).

(3) Véase, Santos, 2010.

(4) La expresión víctimas del desarrollo ha sido tomada de un interesante número de la revista "El otro derecho" del Instituto Latinoamericano para una Sociedad y un Derecho Alternativos (ILSA), titulado Las víctimas del desarrollo: discusiones para la acción colectiva (2015).

(5) Sobre la noción de distribución desigual de los riesgos en materia ambiental, véase Auyero y Swistum, 2008, p. 216 y ss. 
de la constitución económica, entonces, entra en intersección y tensiona con los pactos políticos consagrados en los textos constitucionales.

En esa intersección se inscriben los interrogantes de este trabajo, que tiene como objetivo identificar cierta tipología de conflictos ambientales jurídicamente relevantes susceptible de producirse en los países latinoamericanos y reflexionar acerca de las incidencias de ese dato sobre el campo del Derecho.

Hablaremos de conflictos ambientales, genéricamente, como aquellos referidos al uso y aprovechamiento de los recursos naturales y a los efectos que ello provoca sobre el ecosistema y las personas que lo habitan.

Siguiendo a Remo F. ENTELMAN (2005, p. 49), pensaremos la noción de conflicto como aquella clase de relación social en la que sus miembros tienen objetivos incompatibles entre sí. Al integrar el género de las relaciones sociales, los conflictos son necesariamente situados: sus características están determinadas por el contexto histórico, cultural, social y económico en que se inscriben y desarrollan. Pero eso no suele advertirse suficientemente. FOUCAULT $(1968,1981)$ ha hecho notar (siguiendo en partes a Nietzsche) que solemos naturalizar el pensamiento como si estuviera fuera de la historia, lo que nos lleva a creer que los conceptos, los problemas y las soluciones que creamos son eternos.

Esa especie de perpetuación de la pertinencia del pensamiento genera serios problemas para desarrollar perspectivas críticas que adviertan cuándo han dejado de ser adecuados para el contexto en que les toca influir. Al cambiar las características del problema, va de suyo que las respuestas deben también reconstruirse para conservar lo único que las vuelve eficaces: su capacidad de resolverlos. El espíritu de este trabajo tiene que ver con eso: significar la importancia de partir de una mirada situada de la conflictividad ambiental latinoamericana para pensar y (re)pensar la práctica jurídica.

En la primera parte intentaremos una caracterización situada de los conflictos ambientales latinoamericanos, pretendiendo captar aquellos patrones que -aún sin ser los únicos posibles- predominan en ellos (II). Nos referiremos por un lado al modelo de desarrollo que predomina en los países de la región (1) y por el otro al marco normativo que sus constituciones han definido, configurando un acervo común de protección ambiental (2).

Transitado ese recorrido, culminaremos el presente trabajo reflexionando sobre las incidencias sobre el campo del derecho del dato común previamente identificado (III). La pregunta que guiará esas líneas es la siguiente: ¿qué aspectos deberíamos tener en cuenta para construir en América Latina un sistema jurídico y una práctica situada en materia de conflictividad ambiental? 


\section{Conflictividad ambiental latinoamericana: un contexto económico y normativo para una mirada situada}

\subsection{Cuestión ambiental y desarrollo económico en América Latina}

América Latina posee una enorme riqueza ecológica. Extensas superficies boscosas ocupan el $45 \%$ del área terrestre de la región, albergando la mitad de los bosques tropicales del mundo. Entre un tercio y la mitad de las especies animales conocidas habitan sus suelos. El agua subterránea y superficial que corre por estas tierras importa el $30 \%$ de toda el agua dulce disponible en el planeta y aproximadamente el $40 \%$ de los recursos hídricos renovables. ${ }^{(6)}$

Esos son sólo algunos datos que bosquejan la dimensión de las características ambientales de la región, que registra una diversidad de ecosistemas única. ${ }^{(7)}$ Esa es también la base de marcha de una idea-fuerza que nos acompaña desde el comienzo de la historia del desembarco occidental en estas tierras: esos bienes deben ser introducidos en el comercio, para abrir las puertas a lo que en un momento se llamó progreso y hoy se denomina desarrollo. Debido a la ventaja comparativa que esos recursos les confieren en el mercado internacional, los países latinoamericanos deberían desarrollarse sirviéndose de ellos para intercambiarlos con los demás países del globo. ${ }^{(8)}$

Esa idea-fuerza, sostiene GUDYNAS (2015, p.18), conlleva un modo antropocéntrico de entender la Naturaleza, orientado a manipular el ambiente y buscar la utilidad que le puede reportar a los seres humanos, colocándolos como punto de partida para cualquier valoración, interpretando y sintiendo el ambiente en función de sus necesidades y deseos. Mientras que su conversión en acciones ha sumido a esos bienes -explica el autor- en una intensa explotación por los usos mineros, agrícolas y ganaderos que siguen siendo componentes claves en las economías nacionales (GUDYNAS, 2004, p. 5).

Ello a tal punto que la historia económica de la región ha sido caracterizada como "la del uso (y abuso en ciertas instancias) de sus recursos naturales, desde

(6)

Véase, Programa de las Naciones Unidas para el Medio Ambiente (PNUMA), Informe Perspectivas del medio ambiente: América Latina y el Caribe, 2010, disponible en: http://www.pnuma.org/geo/ geoalc3/Doc\%20COMPLETO/GEO\%20ALC\%203\%20WEB\%20VERSION\%20C.pdf, último acceso: 06 de marzo de 2017.

(7) La región "[...] abarca desde el gran ecosistema de la cuenca del Amazonas, que pertenece predominantemente al trópico húmedo, hasta las características templado-frías de la Patagonia, pasando por el Chaco, el páramo, la prepuna, la puna, el cerrado, al alto andino, el paraense, las yungas, el Pacífico, el venezolano, el Atlántico, las Guayanas, el central mexicano, el desierto del Pacífico, el desierto mexicano, el centroamericano de altura, el centroamericano del Caribe, el espinal, el monte sudamericano, la pampa, el tropical de Centroamérica, la Guajira, el subantártico, hasta el gran ecosistema insular del Caribe" (Ibíd., pág. 21).

(8) Véase Svampa y Viale, 2014, p. 23; y Programa de las Naciones Unidas para el Medio Ambiente, supra nota 7, pág. 33. 
las explotaciones mineras y de plantación de los siglos XVII y XVIII, a los modelos monoexportadores del siglo XIX, los procesos de industrialización de post-guerra, el periodo de privatización y reformas estructurales de los 80's y 90's, como así también durante el actual período caracterizado por una rápida globalización de las economías".(9)

En la actualidad se advierte una profundización de esa tendencia. Los países latinoamericanos tienen en funcionamiento proyectos de desarrollo económico basados en la extracción y procesamiento de recursos naturales, que de la mano de los avances tecnológicos están logrando expandirse. ${ }^{(10)}$

Si bien esos países están integrados en la economía global de una manera relativamente desigual, debido a la incidencia de factores como la geografía, el clima, la tecnología y la infraestructura disponibles (entre otros), esta integración tiene un patrón común: la predominancia de actividades económicas primarias (como la agricultura, la ganadería, la explotación forestal, la pesca, la caza y la minería) o secundarias relacionadas con la extracción y procesamiento de recursos naturales (como la explotación hidrocarburífera). Es decir actividades extractivas basadas en la explotación de los recursos naturales disponibles en cada país. ${ }^{(11)} \mathrm{A}$ ese esquema se suma la utilización de esos recursos para la generación de energías renovables, como la energía hidráulica que se vale de represas que desvían enormes cursos de ríos modificando por completo los ecosistemas del lugar donde se asientan.

Más de la mitad de lo que exporta la región (un 54\%) son bienes primarios con escaso o nulo procesamiento, tales como minerales, hidrocarburos (gas natural y petróleo), productos agrícolas y ganaderos, forestales y pesqueros. Si se quita a México de la cuenta (cuyas exportaciones son un $74 \%$ manufacturas), casi el $73 \%$ de las exportaciones de la región son bienes primarios basadas en recursos naturales. En algunos países, incluso, las exportaciones de productos primarios sobrepasan el $95 \%$ del total exportado. Los diez principales productos de exportación de la mayoría de los países son bienes primarios mineros y agrícolas. ${ }^{(12)}$ Ese patrón hace que el continente se esté comportando como un "proveedor global de biocapacidad".(13)

(9) Programa de las Naciones Unidas para el Medio Ambiente, supra nota 7, pág. 23.

(10) Comisión Económica para América Latina y el Caribe (CEPAL), Organización de las Naciones Unidas para la Agricultura y la Alimentación (FAO) e Instituto Interamericano de Cooperación para la Agricultura (IICA), Perspectivas de la agricultura y del desarrollo rural en las Américas: una mirada hacia América Latina y el Caribe 2015-2016. San José, CEPAL, FAO e IICA, 2015, pág. 55, disponible en: http://repositorio.cepal.org/bitstream/handle/11362/39023/4/PerspectivasAgricultura2015-16_es.pdf, último acceso: 06 de marzo de 2017.

(11) Siguiendo a GUDYNAS, referiremos a extractivismo o actividad extractiva para describir aquella práctica consistente en la remoción o extracción de grandes volúmenes de recursos naturales, como minerales, hidrocarburos o agroalimentos, para su exportación como materias primas a los mercados globales, sin ser procesada, o con un procesamiento o industrialización muy limitada. (GUDYNAS, 2010, p. 40.) (12) Programa de las Naciones Unidas para el Medio Ambiente, supra nota 7, pág. 34. Según el informe citado, todas esas estimaciones se basaron en datos producidos por la CEPAL correspondientes al año 2009. Las excepciones con una mayor diversificación se encuentran en Brasil, El Savador, Argentina y México. (13) GUDYNAS, supra nota 10, pág. 16. 
En América del Sur la especialización en materias primas varía de país en país. Chile y Perú se concentran en metales. En Venezuela, Ecuador, Colombia, Bolivia y México predominan las exportaciones de hidrocarburos. En Uruguay, Paraguay y Argentina las exportaciones de alimentos. En Brasil los alimentos son el mayor rubro exportador dentro de las materias primas en Brasil, aunque los metales, particularmente el mineral de hierro, aumentan su importancia. ${ }^{(14)}$

Ese patrón -esbozado en sus aspectos más generales- ha ofrecido durante los últimos años la posibilidad de obtener importantes recursos económicos a través del comercio internacional, de la mano de los elevados precios de las materias primas, los cuales se han transformado tanto en ingresos fiscales para las unidades estatales como ganancias para los actores privados que llevan adelante la mayoría de las respectivas actividades. ${ }^{(15)}$

La profundización de ese modelo comercial ha incrementado la presión sobre los recursos naturales, produciendo un progresivo deterioro en ellos y disminuyendo la diversidad biológica que caracteriza a la región. ${ }^{(16)}$ Ese efecto importa fuertes y constantes tensiones entre las necesidades ambientales y las demandas por el aprovechamiento económico, las cuales están arrojando como resultado la multiplicación del saldo neto de deterioro ambiental.

Los costos ambientales pagados por los países latinoamericanos para sostener los modelos de desarrollo de corte extractivistas son inmensos y se manifiestan en los diversos elementos del ecosistema. Sin pretender ser exhaustivos, apuntaremos algunos de ellos para lograr una idea aproximada de las dimensiones de lo que estamos hablando.

Uno de los fenómenos que inciden más negativamente sobre el ecosistema, en particular sobre la diversidad biológica, es la expansión de la frontera agrícola, es decir la ampliación del territorio destinado al cultivo de diferentes bienes primarios que luego serán comercializados en el mercado internacional como commodities.

\footnotetext{
(14) Comisión Económica para América Latina y el Caribe (CEPAL), Perspectivas económicas de América Latina 2014. Logística y competitividad para el desarrollo, San José, CEPAL, 2014, pág. 39, disponible en http://repositorio.cepal.org/bitstream/handle/11362/1504/1/LCG2575_es.pdf, último acceso: 06 de marzo de 2017.

(15) Los precios de los bienes primarios a nivel internacional han disminuido recientemente y está previsto que esa tendencia se mantenga, lo cual está provocando importantes crisis en las economías de este lado del mundo y la necesidad de redefinir los rumbos económicos. En respuesta a ese panorama, organismos especializados promueven que ello sea acompañado de un aumento de la producción a partir de la conjunción de dos factores: un aumento en la productividad y un aumento en la cantidad de recursos naturales afectados a la producción. Véase Comisión Económica para América Latina y el Caribe (CEPAL), Organización de las Naciones Unidas para la Agricultura y la Alimentación (FAO) e Instituto Interamericano de Cooperación para la Agricultura (IICA), supra nota 10, págs. 52 y 57-8. (16) Programa de las Naciones Unidas para el Medio Ambiente, supra nota 7, pág. 23.
} 
Para que ese fenómeno expansivo suceda se modifican los usos de los suelos, lo cual viene generando su degradación y un aumento del riesgo de que sean contaminados con químicos utilizados para las fumigaciones.

El lugar donde antes había bosques nativos pasa a convertirse en un lugar de cultivo, para lo cual se deforestan árboles y la fauna y la flora que habitaba el lugar se ve desplazada o eliminada. Según la FAO, la agricultura comercial originó casi el 70\% de la deforestación en América Latina en el período 2000-2010. En la Amazonía la producción de agronegocios para los mercados internacionales se ha identificado como principal factor de la deforestación posterior a 1990. ${ }^{(17)}$ "La expansión de los pastos causó la pérdida de al menos un tercio de los bosques en todos los países excepto en Perú, donde la expansión de las tierras de cultivo en pequeña escala (situada en un $41 \%$ ) constituyó un factor más dominante. En Argentina, la expansión de los pastos provocó la pérdida de aproximadamente el $45 \%$ de los bosques a lo largo del período en cuestión y la expansión de las tierras de cultivo comerciales, más del $43 \%$. Más del $80 \%$ de la deforestación en Brasil durante el mismo período se asoció a la conversión en tierra de pastoreo"."18)

Alrededor del $64 \%$ de la pérdida global de bosques ocurrida entre 2000 y 2005 se llevó a cabo en esta región. En las regiones insulares, en cambio, la expansión de la infraestructura para la urbanización y el turismo son las mayores causas de deforestación. ${ }^{(19)}$

Como efecto asociado a la deforestación, surge el problema de la pérdida de la diversidad biológica. La flora y la fauna que antes vivía en los territorios abarcados por la siembra pierden sus condiciones de subsistencia. La expansión de la frontera agropecuaria sobre áreas silvestres afecta la biodiversidad al reducir dichas áreas y fragmentar los ecosistemas remanentes, con sus secuelas de contaminación por agroquímicos, alteraciones en el ciclo del agua o pérdida de la calidad de suelos".(20)

Todas estas actividades, además, importan el uso intensivo del agua que circula en la región. Según la FAO, la extracción de agua anual total para América del Sur, Centroamérica y Caribe corresponde al 6.3 por ciento de las extracciones mundiales, mientras que América del Sur representa el 88 por ciento del total regional. El 71 por ciento de la extracción de agua se utiliza con fines agrícolas en la región. ${ }^{(21)}$

(17) Organización de las Naciones Unidas para la Agricultura y la Alimentación (FAO), Sitio web AQUASTAT (http://www.fao.org/nr/water/aquastat/main/indexesp.stm), último acceso 06 de marzo de 2017. (18) Organización de las Naciones Unidas para la Agricultura y la Alimentación (FAO), El estado de los bosques del mundo 2016. Los bosques y la agricultura: desafíos y oportunidades en relación con el uso de la tierra, Roma, 2016, pág. 22, disponible en: http://www.fao.org/3/a-i5588s.pdf, último acceso: 06 de marzo de 2017.

(19) Programa de las Naciones Unidas para el Medio Ambiente, supra nota 7, págs. 37 y 77.

(20) Programa de las Naciones Unidas para el Medio Ambiente, supra nota 7, pág. 37.

(21) Organización de las Naciones Unidas para la Agricultura y la Alimentación, supra 17. 
Agua que, por otra parte, es sometida a elevados riesgos de ser contaminada. La intensificación de la producción agrícola trae asociada una mayor intensidad en el uso de insumos como ciertos agroquímicos liberados sobre zonas sembradas con semillas genéticamente modificadas. En Perú y Colombia, se observa la disminución gradual de la calidad del agua, debido al vertimiento de la industria minera y pasivos ambientales localizados en las nacientes de las cuencas. En la cuenca del río Amazonas la contaminación del agua y la degradación de su calidad es producto principalmente del uso indiscriminado de pesticidas agrícolas, los cultivos ilícitos, el dumping de los residuos sólidos, la minería y el tratamiento inadecuado de las aguas residuales de las zonas pobladas. ${ }^{\mathbf{( 2 2 )}}$

Esos costos ambientales que pagamos por la ejecución de los modelos de desarrollo también conllevan elevados costos sociales, entendiendo por ellos afecciones a las condiciones de vida y la salud de las personas. Los primeros sujetos que los sufren sobre aquellos que tienen como centro de vida a los ecosistemas presionados, o quienes simplemente habitan en ellos. Nos referimos, por ejemplo, a los pequeños campesinos y, fundamentalmente, a los pueblos indígenas.

Según datos sistematizados por la CEPAL, a partir de censos nacionales de los países de la región, existen en Latinoamérica al menos 44,8 millones de personas identificadas como indígenas. Los países que más población indígena reportan son México y Perú (con casi 17 millones y 7 millones, respectivamente). Les siguen Bolivia y Guatemala, Chile y Colombia (con cifras que rondan los 6 millones) y por último Argentina, Brasil y Ecuador (con alrededor de 1 millón de personas cada uno). En conjunto estas personas integran, estimativamente, 826 pueblos indígenas repartidos por todo Latinoamérica. Estos pueblos van desde la Patagonia y la Isla de Pascua y Patagonia, hasta Oasisamérica en el norte de México, pasando por distintas áreas geográficas como Chaco Ampliado, Amazonía, Orinoquia, Andes, Llanura Costera del Pacífico, Caribe Continental, Baja Centroamérica y Mesoamérica. ${ }^{(23)}$

La expansión de la frontera agrícola impacta de lleno en el centro de vida de estos pueblos ya que existe un vínculo directo entre sus costumbres y la tierra en la que habitan. El cambio de uso de los suelos, en particular y la deforestación, suele generar la expulsión de los indígenas de las zonas involucradas.

La expansión de estas actividades colisiona, en general, con formas de producción campesina y sociedades híbridas que dependen en buena medida de los servicios ambientales provistos por la naturaleza, con lo cual se intensifican

(22) Organización de las Naciones Unidas para la Agricultura y la Alimentación, supra 22.

(23) Comisión Económica para América Latina y el Caribe (CEPAL), Los pueblos indígenas en América Latina. Avances en el último decenio y retos pendientes para la garantía de sus derechos, Santiago de Chile, CEPAL, 2014, pág. 98-102, disponible en: http://repositorio.cepal.org/bitstream/handle/11362/37050/4/S1420783_es.pdf, último acceso: 06 de marzo de 2017. 
en forma significativa los conflictos e injusticias socio-ambientales (Pérez Rincón, 2014, p. 253).

\subsection{La cuestión ambiental en las constituciones latinoamericanas}

La cuestión ambiental tiene una presencia unánime en los textos constitucionales latinoamericanos, al punto que es posible hablar de un acervo normativo común. En este apartado recogeremos las principales tendencias, buscando dar con un paneo general.

Si bien los alcances de este estudio son en cierta medida capilares, ya que se limitan a lo expresado en los pactos políticos fundamentales de nuestros países sin analizar la legislación que en cada unidad estatal reglamentan las normas en ellos consagradas, con este paneo entendemos poder mostrar cuáles valores relacionados con lo que nos ocupa tutelan las constituciones latinoamericanas, dándoles relevancia jurídica. Será un paso necesario para, sobre el final de este apartado, pensar la cuestión en clave conflictual (II. 3).

Tienen relevancia jurídica para este texto aquellos hechos $\mathrm{y} / \mathrm{u}$ omisiones que actúen o puedan actuar como el presupuesto fáctico de ciertas normas jurídicas (TARUFFO, 2009, p. 46). Ello con independencia del grado de determinación que revistan esas normas, que en el caso de los principios constitucionales suele ser reducido y sujeto a una labor determinativa posterior de parte de la judicatura (ALEXY, 1997, p. 81 ss.). En este último caso la relevancia tenderá a ser potencial, supeditada a una determinación posterior por parte de la autoridad jurisdiccional, debido a las particularidades de la técnica de interpretación y aplicación creado para ese tipo de normas (y todavía en construcción) por la filosofía jurídica a fines del siglo XX, el juicio de ponderación (ALEXY, 1997, p. 81 ss.; ALEXY, 2006, p. 5 y ss.).

Un conflicto tendrá relevancia jurídica, entonces, cuando los hechos que lo conforman a la vez integren o puedan integrar (por estar sujetos a una posterior determinación judicial) la estructura normativa de una o varias normas jurídicas.

Este relevamiento por las constituciones latinoamericanas ha sido enfocado en su recepción de diversos valores relacionados con lo ambiental o que, sin serlo directamente, se ponen en juego con los impactos de las actividades antrópicas sobre el ambiente. ${ }^{(24)}$ Al finalizar este apartado estaremos en condiciones de identificar aquellos conflictos susceptibles de tener relevancia jurídica y sobre esa base reflexionar, en el apartado que sigue, acerca del impacto de ese dato en el campo del derecho (III).

(24) Tal actividad ha sido notablemente facilitada por el motor de búsqueda desarrollado por el Comparative Constitutions Project (https://www.constituteproject.org). También han servido de guía dos obras surgidas en el marco del Programa de las Naciones Unidas para el Medio Ambiente (PNUMA): Brañes, 2001 y Rey Santos, 2010. 
A continuación, se presentará una sistematización de las principales conclusiones recabadas, empezando con la siguiente figura (Figura 1) que representa en su eje vertical los valores sondeados y en su eje horizontal la cantidad de textos constitucionales que los han recibido.

- Figura 1 -

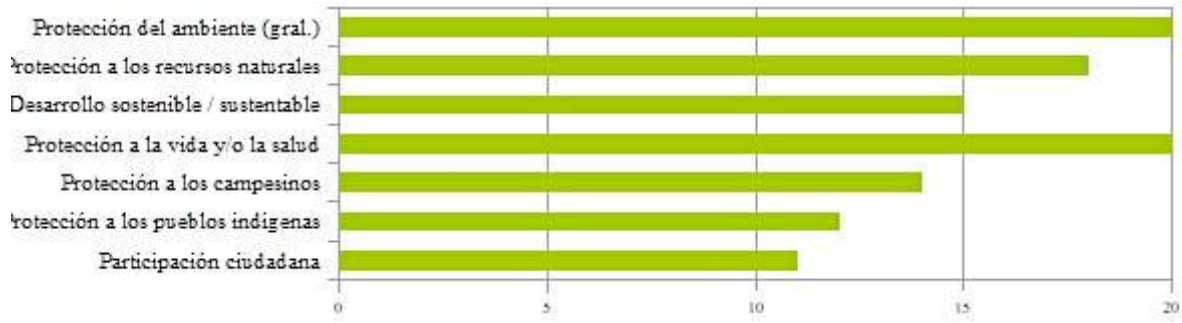

Las constituciones latinoamericanas relevadas han sido dictadas mayormente a partir de la segunda mitad del siglo XX. Las dictadas antes (la mexicana, 1917, y la costaricense, 1949) fueron pasibles de sustanciales reformas hasta tiempos recientes, que -entre otros aspectos- jerarquizaron los tratados internacionales. La oleada más grande de reformas, sin embargo, se desató en los años 80 y sigue hasta la actualidad. Sus últimos estandartes son las constituciones de Ecuador (2008), Bolivia (2009) y República Dominicana (2015). ${ }^{\text {(25) }}$

En relación con el tema que nos ocupa puede afirmarse que las constituciones latinoamericanas han abordado unánimemente la cuestión ambiental, advirtiéndola como un aspecto de necesaria regulación. Todas las constituciones hacen referencia, de uno u otro modo, a la protección del ambiente como un valor fundamental de la vida en nuestras sociedades, definición que -en concurrencia con otros factores- ha ayudado al desarrollo del derecho ambiental dentro de los respectivos estados y promovido la recepción de la conflictividad ambiental en el seno de los tribunales de justicia.

Lo que sigue se ocupará de desgranar los valores sondeados en los textos constitucionales.

Como se dijo, todas las constituciones relevadas tienen pasajes en los cuales consagran como un valor la protección del ambiente en general. Muchas postulan como un derecho de las personas el goce de un ambiente sano, ${ }^{(26)}$ mientras que otras colocan en cabeza del Estado el deber de su protección frente a actos que lo

(25) A este panorama hay que sumar la posible reforma de la constitución chilena, proyecto que está siendo impulsado por la actual gestión de gobierno.

(26) México (art. 4), Nicaragua (art.60), Costa Rica (art. 50), República Dominicana (art. 67), Colombia (art. 79), Venezuela (art. 127), Ecuador (art. 14), Perú (art. 2), Bolivia (art. 33), Paraguay (art. 7), Chile (art. 19) y Argentina (art. 43). 
contaminen o degraden. ${ }^{(27)}$ En esa línea, algunas constituciones prevén como una necesidad la protección del equilibrio ecológico ${ }^{(\mathbf{2 8})}$ y la diversidad biológica ${ }^{(29)}$. Se destaca en este punto la constitución ecuatoriana que, además de la perspectiva antropocéntrica de consagrar la protección ambiental con un derecho de las personas, adopta una óptica ecocéntrica confiriéndole a la naturaleza el carácter de sujeto de derechos (arts. 10 y 71 a 74), incluso asignándole el derecho a ser restaurada (art. 72), e imponiendo como un deber de los ecuatorianos el respeto de las prerrogativas que goza (art. 83).

Además de esas referencias genéricas al valor protección ambiental, pueden encontrarse en muchas constituciones latinoamericanas referencias a la protección de ciertos recursos naturales y a la sustentabilidad del desarrollo económico.

El $90 \%$ de las constituciones relevadas ( 18 de ellas) además de la protección al ambiente tienen referencias a la protección de los recursos naturales en general y de algunos de ellos en particular, imponiéndole al Estado eso como un deber. Así sucede con el agua (considerada tanto como elemento de consumo personal como recurso hídrico con potencial energético), con el suelo y particularmente con los bosques. ${ }^{\left({ }^{(3)}\right)}$ Respecto a estos últimos algunas constituciones definen como una prioridad política la reforestación y su conservación. ${ }^{(31)}$ Priman los abordajes que parten de la necesidad de su utilización y consagran como una condición que la misma sea sustentable, evitando que los mismos se degraden, contaminen o desaparezcan. Ello traza una relación entre la protección de los recursos y la cuestión del desarrollo.

Un 75\% de las constituciones relevadas (15 de ellas) establecen de modo expreso -con diferentes fórmulas- que el desarrollo económico deberá ser sustentable. Si bien prevén que el Estado deberá utilizar los recursos naturales para lograr esa meta, incluso algunas declaran como una prioridad nacional que

(27) Guatemala (art. 97), Honduras (art. 145), El Salvador (art. 117), Panamá (art. 114), Cuba (art. 27), República Dominicana (art. 67), Colombia (arts. 8 y 80), Venezuela (art. 127), Ecuador (arts. 72, 406, 411 y 414), Brasil (art. 23), Bolivia (art. 9.6). La constitución uruguaya, por su parte, prohíbe a las personas contaminar gravemente el ambiente y deja librado a una ley posterior la reglamentación de esa manda (art. 47), en virtud de lo cual fue dictada la ley 17.283 (2000) que consagra -entre otros aspectos- el derecho de todos los habitantes a ser protegidos en el goce de un ambiente sano y equilibrado (art. 2) y el deber del Estado de protegerlo (art. 3).

(28) México (arts. 4 y 73.XXIX), Guatemala (art. 97), Panamá (art. 115), Haití (art. 253), República Dominicana (art. 67), Venezuela (art. 127), Brasil (art. 225) y Bolivia (art. 380).

(29) Perú (art. 68), Bolivia (art. 348) y Argentina (art. 43).

(30) México (arts. 4 y 27), Guatemala (art. 97), Panamá (art. 114 y 118), Cuba (art. 27), República Dominicana (arts. 17 y 61), Colombia (art. 80), Venezuela (arts. 127 y 156), Ecuador (arts. 3, 406, 409, 411 y 414), Perú (art. 67), Brasil (arts. 225.1 y 231.3), Bolivia (arts. 9.6, 16, 311.2 y 359), Uruguay (art. 47) y Argentina (art. 41).

(31) Guatemala (art. 126), Honduras (art. 340), Haití (art. 253.1) y República Dominicana (art. 17). 
se exploten los recursos naturales no renovables a través de ciertas actividades, ${ }^{(32)}$ también establecen el deber de que esa utilización resulte sustentable, evitando la depredación de los mismos. ${ }^{(33)}$ Algunos textos constitucionales más recientes han incorporado expresamente como condición para el desarrollo de actividades susceptibles de generar daños al ambiente la realización de estudios de impacto ambiental. ${ }^{(34)}$

Puede advertirse la tensa convivencia de dos ideas: una que indica que el desarrollo económico de nuestros países depende de la explotación de los recursos naturales, y otra que postula que esos recursos deben ser cuidados, dada la importancia para la vida y desarrollo de las personas de contar con un ambiente sano. Esa es una profunda tensión interna de los textos constitucionales, entre los cuales los de Bolivia y Ecuador muestran mayores tendencias a favor de la segunda de las ideas. Pero la tensión más potente no es interna, sino que sucede cuando se compulsan los textos constitucionales con los modelos de desarrollo económico efectivamente aplicados, es decir con la realidad ambiental latinoamericana que -como reseñamos antes- ha venido siendo fuertemente determinada por la primera de las ideas.

Además de esos valores directamente relacionados con la cuestión ambiental, se ha sondeado la inclusión en las constituciones latinoamericanas de otros valores que podrían ser afectados con los impactos de la actividad

(32) La constitución guatemalteca dispone declarar “[...] de utilidad y necesidad públicas, la explotación técnica y racional de hidrocarburos, minerales y demás recursos naturales no renovables" (art. 125). La constitución colombiana ha creado un fondo nacional de regalías por la explotación de los recursos naturales no renovables cuyos fondos "se aplicarán a la promoción de la minería, a la preservación del ambiente" (art. 361).

(33) La constitución guatemalteca, por ejemplo, estipula: “Es obligación del Estado orientar la economía nacional para lograr la utilización de los recursos naturales y el potencial humano" (art. 118); "Se dictarán todas las normas necesarias para garantizar que la utilización y el aprovechamiento de la fauna, de la flora, de la tierra y del agua, se realicen racionalmente, evitando su depredación" (art. 97). La constitución hondureña tiene el siguiente pasaje:"Se declara de utilidad y necesidad pública, la explotación técnica y racional de los recursos naturales de la Nación" (art. 340). La constitución salvadoreña dispone: "El Estado promoverá el desarrollo económico y social mediante el incremento de la producción, la productividad y la racional utilización de los recursos" (art. 101). El texto constitucional dominicano, por su parte, declara "de alto interés público la exploración y explotación de hidrocarburos" que "sólo pueden ser explorados y explotados por particulares, bajo criterios ambientales sostenibles" (art. 17), y estipula que el régimen económico "[s]e fundamenta en el crecimiento económico, la redistribución de la riqueza, la justicia social, la equidad, la cohesión social y territorial y la sostenibilidad ambiental, en un marco de libre competencia, igualdad de oportunidades, responsabilidad social, participación y solidaridad" (art. 217). La constitución brasileña prevé: "Los que explotasen recursos minerales quedan obligados a reponer el medio ambiente degradado, de acuerdo con la solución técnica exigida por el órgano público competente" (art. 225.2). El texto constitucional boliviano, lo siguiente: "Los recursos naturales renovables se aprovecharán de manera sustentable, respetando las características y el valor natural de cada ecosistema" (art. 380).

(34) Venezuela (art. 129) y Brasil (art. 225.1). En los demás países latinoamericanos esta condición ha tendido a ser incorporada en sus respectivas legislaciones ambientales. 
antrópica sobre el ambiente, o con los procesos de evaluación y decisión sobre la correspondencia de las mismas.

El primero de esos valores repara en la protección a la vida y/o a la salud. Todas las constituciones relevadas los definen (aunque con sensibles variaciones de intensidad) como derechos de las personas que deben ser protegidos por el Estado. ${ }^{(35)}$ Esa decisión normativa surte múltiples efectos, algunos de los cuales se extienden sobre la cuestión ambiental. Ello dado que la indivisibilidad entre el ser humano y el ambiente que lo rodea hace que las condiciones ambientales surtan efectos directos sobre la salud y vida de las personas. ${ }^{(36)}$ Entonces, no es difícil considerar que una de las condiciones para conservar la vigencia de esos derechos es que el ambiente que nos rodea tenga mínimas condiciones de habitabilidad. ${ }^{\text {(37) }}$

También se han identificado muchas constituciones que avanzan sobre la protección a los campesinos. El $70 \%$ de las constituciones relevadas (14 de ellas) han recogido de alguna manera la problemática de los campesinos en nuestros países, disponiendo hacia ellos un trato particular que redunda en una especial protección. Muchos textos se enfocan en el deber estatal de promover condiciones para el desarrollo integral del sector rural y la garantía del bienestar de los campesinos, en la provisión de ayuda técnica y económica hacia ellos o en su necesaria participación de los debates sobre políticas nacionales y sectoriales. ${ }^{(\mathbf{3 8})}$ Bolivia y Honduras incluso disponen que -al igual que los pueblos indígenastienen derecho a que se los consulte frente a la adopción de medidas legislativas que pudieran afectarles (arts. 30.2 y 345, respectivamente)

Otro de los valores sondeados tiene que ver con la protección a los pueblos indígenas. ${ }^{(39)}$ Un $60 \%$ de las constituciones relevadas (12 de ellas) hace

(35) Hay una importante oscilación entre países que lo hacen con una alta intensidad (como Colombia, Ecuador y Brasil, por poner ejemplos) y otros que muestran una intensidad reducida, colocando en cabeza del Estado el deber de legislar mecanismos para acceder a ella (como Chile y Uruguay).

(36) Por ejemplo, si una mina vuelca residuos químicos al curso de agua del que se extrae el agua para consumo de una población lindera estaremos frente a un hecho de contaminación ambiental, del recurso natural agua, que incide directamente en la salud -y en el peor de los casos en la vida- de las personas que consumen ese recurso.

(37) La Comisión Interamericana de Derechos Humanos ha dictado dos resoluciones cautelares (la MC 271/05, que ha sido ampliada en este año) a favor de la población de La Oroya, Perú, por la contaminación ambiental con plomo producida por complejos metalúrgicos asentados en la zona. Al hacerlo tomó como fundamento que "[...] la información disponible indica que los beneficiarios sufren de una serie de afectaciones a la salud a consecuencia de altos índices de contaminación del aire, suelo y agua en la comunidad de La Oroya, producto de partículas de metales liberadas por el complejo de empresas metalúrgicas allí instaladas". Es decir que advirtió la indivisible relación entre ambiente y salud.

(38) México (art. 27), Guatemala (art. 119), Honduras (art. 345), Nicaragua (art. 111), Panamá (arts. 120 y 122), República Dominicana (art. 51.3), Colombia (art. 54), Venezuela (art. 307), Ecuador (art. 282), Perú (art. 89), Bolivia (arts. 2 y 30.2) y Paraguay (arts. 114 y 115).

(39) Por un análisis detallado y sistemático de todas las constituciones latinoamericanas en la materia, véase: Yrigoyen Fajardo, 2011. 
mención a los pueblos indígenas como grupos que requieren cierta protección y son titulares de derechos específicos relacionados con sus necesidades. Algunas ponen en cabeza del Estado el deber de adoptar medidas tendientes a promover la igualdad de oportunidades para los integrantes de estos pueblos y favorecer su desarrollo integral. ${ }^{\mathbf{( 4 0 )}}$ La mayoría de ellas dispone reconocer y garantizar a favor de estos pueblos su derecho a la libre determinación y autonomía, el derecho a la posesión y conservación ambiental de sus territorios y el derecho a la preservación de su identidad y cultura (que suele incluir la tierra donde viven) ${ }^{(\mathbf{4 1})}$. Ciertas constituciones, de modo notable para lo que nos ocupa, también han regulado la relación entre los territorios indígenas y la explotación de sus recursos naturales, disponiendo la necesaria consulta previa e informada de toda actividad que quisiera realizarse en ese sentido y el impedimento a que como consecuencia de ellas esos recursos sean degradados, afectando también así la identidad y la cultura de las poblaciones. ${ }^{(42)}$

El último de los valores a destacar aquí consiste en la participación ciudadana. El 55\% de las constituciones relevadas (11 de ellas) han propendido a diseñar sistemas democráticos más participativos -alejándose de las concepciones elitistas de la democracia- a través de la apertura de instancias de participación y debate en el marco de la gestación, implementación y control de políticas en general, de la materia ambiental en particular e, incluso, referidas a ciertos

(40) México (art. 2), Panamá (art. 120) y Bolivia (art. 264).

(41) México (art. 2), Guatemala (arts. 66 y 67), Honduras (art. 346), Nicaragua (art. 5), Panamá (art. 123), Venezuela (arts. 119 y 122), Ecuador (art. 57), Bolivia (arts. 2 y 30.2), Paraguay (arts. 62 a 65) y Argentina (art. 75.17).

(42) La constitución colombiana establece: “La explotación de los recursos naturales en los territorios indígenas se hará sin desmedro de la integridad cultural, social y económica de las comunidades indígenas. En las decisiones que se adopten respecto de dicha explotación, el Gobierno propiciará la participación de los representantes de las respectivas comunidades" (art. 330). La constitución venezolana que: "El aprovechamiento de los recursos naturales en los hábitats indígenas por parte del Estado se hará sin lesionar la integridad cultural, social y económica de los mismos e, igualmente, está sujeto a previa información y consulta a las comunidades indígenas respectivas. Los beneficios de este aprovechamiento por parte de los pueblos indígenas están sujetos a la Constitución y a la ley" (art. 120). La constitución ecuatoriana, por su parte, dispone que es un derecho de las nacionalidades indígenas "[l]a consulta previa, libre e informada, dentro de un plazo razonable, sobre planes y programas de prospección, explotación y comercialización de recursos no renovables que se encuentren en sus tierras y que puedan afectarles ambiental o culturalmente" (art. 57). La constitución brasileña estipula: "El aprovechamiento de los recursos hidráulicos, incluido el potencial energético, la búsqueda y extracción de las riquezas minerales en tierras indígenas sólo pueden ser efectuadas con autorización del Congreso Nacional, oídas las comunidades afectadas, quedándoles asegurada la participación en los resultados de la extracción, en la forma de la ley" (art. 231.3). La constitución boliviana marca que los pueblos indígenas tienen el derecho "[a] ser consultados mediante procedimientos apropiados, y en particular a través de sus instituciones, cada vez que se prevean medidas legislativas o administrativas susceptibles de afectarles" (art. 30.2) y que "[s]e garantiza la participación ciudadana en el proceso de gestión ambiental y se promoverá la conservación de los ecosistemas" (art. 352). Para la constitución argentina corresponde al congreso nacional "[a]segurar su participación [la de los pueblos indígenas] en la gestión referida a sus recursos naturales y a los demás intereses que los afecten" (art. 75.17). 
recursos. Algunas de las normas, además, han sido destinadas en especial a ciertos sujetos $^{(\mathbf{4 3})}$.

Esbozados los resultados de ese paneo por el acervo de protección ambiental constitucional latinoamericano, cuadra completar el panorama con la referencia a ciertos instrumentos internacionales que son particularmente relevantes para la temática que nos ocupa.

En lo que respecta a la materia ambiental no podemos dejar de mencionar dos documentos surgidos en el marco de la ONU que han colocado los pilares del derecho ambiental en todo el mundo: la Declaración de Estocolmo de 1972 y la Declaración de Río de Janeiro de 1992.

La última de ellas es la más detallada, al consagrar con pretensión universal los principios de desarrollo sostenible (principio 3), los de prevención y precaución (principio 15), y los derechos a la información y a la participación en la formulación de políticas, toma de decisiones, gestión y control ambientales y control de políticas ambientales (principio 10). ${ }^{(44)}$

En lo que respecta al derecho a la vida y al derecho a la salud son de especial relevancia tres tratados internacionales que los consagran y han sido suscritos por todos los países latinoamericanos: el Pacto Internacional de Derechos Económicos, Sociales y Culturales (PIDESC), el Pacto Internacional de Derechos Civiles y Políticas (PIDCyP) y la Convención Americana de Derechos Humanos (CADH).

(43) La constitución mexicana lo prevé para los debates acerca del "uso equitativo y sustentable de los recursos hídricos" (art. 4). La hondureña establece que todos los planes de reforma agraria deben contar con la efectiva participación de los campesinos (art. 345). La nicaraguense marca que "[l]os campesinos y demás sectores productivos tienen derecho de participar en la definición de las políticas de transformación agraria, por medio de sus propias organizaciones" (art. 111). La panameña prescribe que "[e]l Estado dará atención especial a las comunidades campesinas e indígenas con el fin de promover su participación económica, social y política en la vida nacional" (art. 120). Para la constitución colombiana es uno de los fines del Estado "facilitar la participación de todos en las decisiones que los afectan y en la vida económica, política, administrativa y cultural de la Nación" (art. 2) y en especial respecto al ambiente estipula que "[l]a ley garantizará la participación de la comunidad en las decisiones que puedan afectarlo" (art. 79). El texto venezolano, por su parte, manda que "[l]a participación del pueblo en la formación, ejecución y control de la gestión pública es el medio necesario para lograr el protagonismo que garantice su completo desarrollo" (art. 62). Para la constitución ecuatoriana, todas las personas tienen derecho a participar en los asuntos de interés público y a ser consultado en lo que los afecte (art. 61) y establece que "[l]as ciudadanas y ciudadanos, en forma individual y colectiva, participarán de manera protagónica en la toma de decisiones, planificación y gestión de los asuntos públicos" (art. 95). La constitución boliviana garantiza "[l]a participación ciudadana en el proceso de gestión ambiental y se promoverá la conservación de los ecosistemas" (art. 352). La constitución paraguaya marca como base de la reforma agraria "la participación de los sujetos de la reforma agraria en el respectivo proceso" (art. 115). La constitución uruguaya prescribe que "[l]os usuarios y la sociedad civil, participarán en todas las instancias de planificación, gestión y control de recursos hídricos" (art. 47).

(44) Véase Pastorino, 2005, p. 90 y ss. 
Por último, en lo que respecta a los pueblos indígenas nos encontramos con dos instrumentos internacionales de primera relevancia que estipulan estándares de protección sumamente elevados.

El Convenio 169 de la Organización Internacional del Trabajo sobre pueblos indígenas y tribales (de 1989) pergeña mandatos hacia los gobiernos tendientes, entre otros aspectos, a que éstos asuman la "[...] responsabilidad de desarrollar, con la participación de los pueblos interesados, una acción coordinada y sistemática con miras a proteger los derechos de esos pueblos y a garantizar el respeto de su integridad" (art. 2.1). Esas acciones, marca el Convenio, deberán abarcar como mínimo el goce igualitario de los pueblos indígenas de los derechos sociales, respetando su identidad social y cultural, sus costumbres y tradiciones, y sus instituciones (art. 2.2). Por otro lado, el Convenio prescribe que cada vez que se prevean medidas legislativas o administrativas susceptibles de afectar a estos pueblos, deberán establecer procedimientos apropiados de consulta previa, libre e informada (art. 6). ${ }^{(45)}$

Además de ello, recientemente fue aprobada la Declaración de las Naciones Unidas sobre los derechos de los pueblos indígenas (2007), con el voto favorable de todos los países latinoamericanos. Esa declaración es robusta en derechos y reafirma las líneas sostenidas por el Convenio 169. En especial nos interesa lo prescrito por el art. 32 de la misma: "Los Estados celebrarán consultas y cooperarán de buena fe con los pueblos indígenas interesados por conducto de sus propias instituciones representativas a fin de obtener su consentimiento libre e informado antes de aprobar cualquier proyecto que afecte a sus tierras o territorios y otros recursos, particularmente en relación con el desarrollo, la utilización o la explotación de recursos minerales, hídricos o de otro tipo".

\subsection{Una mirada situada: conflictos ambientales en América Latina}

Hemos dejado sentado que en los modelos de desarrollo latinoamericanos predomina un patrón: se basa en la presión -cada vez mayor- sobre los recursos naturales. Esa presión, se dijo, tiende a provocar elevados costos ambientales y sociales.

También hemos podido advertir que las cartas constitucionales de los países de la región condicionan esos modelos de desarrollo a través de un acervo normativo que protege una serie de valores que, precisamente, son puestos en crisis con la ejecución de esos modelos. Protegen el ambiente, los recursos naturales, la

(45) Además, el Convenio dispone: “Los pueblos interesados deberán tener el derecho de decidir sus propias prioridades en lo que atañe al proceso de desarrollo, en la medida en que éste afecte a sus vidas, creencias, instituciones y bienestar espiritual y a las tierras que ocupan o utilizan de alguna manera, y de controlar, en la medida de lo posible, su propio desarrollo económico, social y cultural. Además, dichos pueblos deberán participar en la formulación, aplicación y evaluación de los planes y programas de desarrollo nacional y regional susceptibles de afectarles directamente" (art. 7). 
vida y la salud de las personas e instauran derechos a la participación en la adopción de esas decisiones. Las constituciones aparecen, así, tensionando los patrones de (mal) desarrollo adoptados por los países de este lado del mundo, trazando límites sobre las decisiones acerca de cuáles costos pagar a cambio de esa meta.

Una mirada conjunta de ambos factores, el económico y el normativoconstitucional, nos da la pauta del contexto en el que se desarrollan los conflictos ambientales que comunes a los países de la región. ${ }^{(46)}$ Nos permite emprender una mirada situada, e identificar una tipología de conflictos ambientales con relevancia jurídica presentes en toda América Latina, es decir conflictos con determinadas características que tienen un elevado nivel de probabilidad de suceder en la región.

El riesgo de deterioro en que el modelo de desarrollo económico latinoamericano coloca al ecosistema, cuyos elementos presiona -cada vez más- para obtener bienes de intercambio en el comercio internacional, vuelve altamente probable que se susciten en nuestro territorio conflictos en torno a la protección de los bienes ambientales. ${ }^{(47)}$ (En ese sentido hablamos de "tipicidad": eventos cuyas características esenciales se repiten.) Conflictos que, a su vez, estarán abarcados por el contenido normativo de los textos constitucionales de la región, que se disponen a resguardar esos mismos valores puestos en crisis por aquellos patrones. Es decir, tendrán relevancia jurídica. ${ }^{(\mathbf{4 8})}$

\section{Conflictividad ambiental latinoamericana y campo del derecho: apuntes sobre problemas de acople}

La conflictividad ambiental latinoamericana, como eventos de sucesión probable en la región, necesita ser significado por el campo del Derecho. Los textos constitucionales lo han hecho en su faz dogmática, dando lugar a un acervo normativo que protege el ambiente y valores coligados. Pero esa definición política no parece haberse vuelto significados ni prácticas en el resto del campo del derecho.

(46) Algunos países de matrices económicas más diversificadas (como México, Brasil y Argentina) también tienen conflictos ambientales provenientes de actividades industriales.

(47) A modo de hipótesis, se puede decir estos conflictos son susceptibles de abarcar extensos territorios y numerosas personas; así como de tener un alto voltaje político y componentes interculturales e intergeneracionales. También que suelen polarizar dos objetivos muchas veces incompatibles: la profundización del modelo de desarrollo extractivista, tendiente a obtener réditos a través del comercio internacional de los recursos naturales, con la cultura y el estilo de vida de indígenas y campesinos, así como la vigencia de los derechos de los ciudadanos en general a un ambiente sano, a la conservación de la diversidad biológica, a la vida y a la salud. Esos objetivos están, como hicimos notar, fuertemente condicionados por el plexo constitucional latinoamericano que tiende a proteger estos últimos valores. (48) Es importante destacar que esa configuración conflictual no es única ni exclusiva de América Latina. No es única porque en estas tierras se registran otros tipos de conflictos, como los provenientes de la incipiente actividad industrial. Tampoco es exclusiva porque en otras regiones es probable que sucedan conflictos similares, como en el continente africano cuyos principales países tienen patrones extractivistas similares. 
Se impone reflexionar, entonces, sobre el problema de acople advertido entre una conflictividad típica de la región, alcanzada por los órdenes normativos más elevados de los países que la integran, y el estado del arte dentro del campo del Derecho. ${ }^{(49)}$

La falta de acople entre estos factores es un problema porque las posibilidades de que esos órdenes normativos incidan en la realidad, objetivo político crucial de todo texto constitucional -y no se conviertan en meras hojas de papel(50) - dependen de la estructura institucional de los estados, en buena medida de aquellos mecanismos que suelen construir para garantizarlo: los sistemas de justicia.

Toda organización estatal carga con cierta capacidad de ingeniería social que le permite promover determinadas relaciones y desincentivar otras (acentuadas o disminuidas según el modelo de Estado imperante), favoreciendo u obstaculizando el logro de determinados objetivos. En un contexto en el cual esos objetivos -o fines- estatales son redefinidos, se justifica y vuelve necesaria una tarea política de refundación que posibilite alcanzarlos. ${ }^{(51)}$

Esa tarea, según advertimos, está incompleta en el campo del Derecho latinoamericano. Los constituyentes pusieron su atención en el reconocimiento de nuevos derechos, pero soslayaron (en su mayoría) el diseño de mecanismos adecuados para que ellos tengan "fuerza normativa" (entendiéndola como la capacidad de provocar prácticas o situaciones concretas). Y ese debilitamiento institucional atenta contra las aspiraciones constitucionales de los Estados de la región en torno a la protección del ambiente. En el marco de la conflictividad ambiental latinoamericana, permite que la relevancia jurídica dada a los valores de los que dimos cuenta tenga dificultades para despegar del papel, siendo incapaz de producir alteraciones en la dinámica de esos conflictos tendientes a su protección.

(49) Hablamos de campo del derecho, bajo la concepción de Pierre Bourdieu, como aquel el campo social donde se articulan instituciones y prácticas a través de las cuales se produce, interpreta e incorpora el derecho. Los campos sociales, afirma el sociólogo francés, son sistemas de posiciones sociales definidas unas en relación con las otras. Dichas posiciones son disputadas por los agentes que integran cada campo, quienes compiten entre sí valiéndose del capital específico con que cuenten. Cada campo social detenta el monopolio de ciertas especies de capital social (v.g. capital político, capital jurídico, etcétera), cuyo manejo se pone en juego con las disputas sobre las posiciones en los campos. (Véase: Bourdieu, 2001.)

(50) Ferdinand Lasalle llamaba así -hojas de papel- a las constituciones. Les quitaba toda trascendencia performativa sobre el poder. Su visión escéptica puede ser resumida en el siguiente pasaje de la famosa conferencia que dictara en Berlín: "La verdadera Constitución de un país no se encierra en unas cuantas hojas de papel escritas, sino en los factores reales de poder, y que son éstos, los resortes de poder, y no el derecho extendido en el papel, los que informan la práctica constitucional, es decir, la realidad de los hechos" (Lasalle, 1999, p. 74)

(51) Véase, Santos, 2010, p. 70. 
Bajo esa óptica, la identificación de una tipología de conflictividad ambiental latinoamericana nos permite pensar en las adaptaciones que necesita el sistema de justicia para canalizar esos conflictos de acuerdo con el acervo normativo de las constituciones de la región, que incluye no sólo derechos a la protección de bienes ambientales sino también derechos a la participación en los espacios de gestión estatal que dirimen los alcances de esa protección. ${ }^{(52)}$

Es así que un importante replanteo le espera por delante a los sistemas procesales, pensados antaño para dirimir conflictos individuales referidos a la propiedad y el contrato. En particular: esa tipología de la que dimos cuenta, cruzada con el acervo normativo latinoamericano, ponen en crisis la noción tradicional de los sujetos procesales, es decir de quienes pueden ser tenidos como partes de un proceso. Para cumplir cabalmente con la impronta participativa de los textos constitucionales en materia ambiental, el derecho procesal necesitará reforzar sus propias capacidades institucionales para obtener sentencias precedidas de robustas instancias de participación.

\section{Conclusiones}

En el camino recorrido hasta aquí se ha intentado reflexionar sobre la conflictividad ambiental latinoamericana y el campo del derecho.

El resultado de esa reflexión puede ser sistematizado en los siguientes puntos.

1. Los modelos de desarrollo de los países de la región latinoamericana comparten un patrón: se basan en la presión -cada vez mayor- sobre los recursos naturales. A tal punto que más de la mitad de las exportaciones de estos países consiste en materias primas con escaso procesamiento previo. Esa presión está reportando elevados costos para los ecosistemas regionales que, entre otros efectos disvaliosos, están perdiendo diversidad biológica y se encuentran sumidos en el cierto de ser pasibles de contaminación. Esos costos ambientales, por otro lado, conllevan indefectiblemente costos sociales: el detrimento ambiental atenta contra los proyectos de vida y la cultura de los pueblos indígenas y las poblaciones campesinas; así como lo hace con contra la salud y la vida de aquellas personas que residen en las zonas de influencia de las actividades involucradas.

(52) Es innegable que las decisiones que se adopten en el marco de los procesos que busquen dirimirlos tendrán relevantes incidencias sobre la gestión estatal de los mismos, determinando -por casosi ciertos emprendimientos pueden funcionar o si tales actos implican daños ambientales y por lo tanto deben ser reparados. Por lo tanto, sería importante que se avance sobre las herramientas procesales de modo que su diseño sea propicio para elevar la calidad democrática de los conflictos en los que intervengan, es decir que impacten de un modo valioso para la vigencia de las aspiraciones constitucionales de los textos políticos de la región. 
A la par de eso, las constituciones latinoamericanas se muestran altamente receptivas de la cuestión ambiental, dado que consagran derechos referidos a la protección del ambiente, de los recursos naturales, y de la salud y la vida de las personas. A la vez, esos textos contienen aspiraciones -que traducen en derechosa que ciertas decisiones se produzcan en el marco de una robusta participación ciudadana, fundamentalmente cuando las mismas afecten a poblaciones indígenas y campesinas. Tal contenido normativo incide sobre los modelos de desarrollo condicionándolos tanto en las consecuencias o costos a pagar como en los procedimientos de decisión sobre su rumbo, a los cuales les exige que sean participativos.

2. La intersección entre modelos económicos y el marco normativo constitucional latinoamericano nos arroja una tipología de conflictos ambientales con relevancia jurídica: eventos así tienen un elevado nivel de probabilidad de suceder en la región.

3. El dato nos permite observar un problema de acople: los sistemas jurídicos no parecen estar lo suficientemente preparados para abordar tales conflictos, generando una dificultad para que la relevancia jurídica dada a los valores constitucionales en materia ambiental se traduzca en alteraciones en la dinámica de esos conflictos tendientes a su protección.

Eso nos lleva a reflexionar acerca de las adaptaciones que necesita el sistema de justicia para canalizar esos conflictos de acuerdo con el acervo normativo de las constituciones de la región, que incluye no sólo derechos a la protección de bienes ambientales sino también derechos a la participación en los espacios de gestión estatal que dirimen los alcances de esa protección. La intervención de los sistemas de administración de justicia en esos conflictos arroja oportunidades sumamente valiosas para los Estados latinoamericanos en orden al cumplimiento de las aspiraciones constitucionales de una elevada calidad democrática en la gestión de los conflictos ambientales.

Entre las diversas aristas que envuelven ese problema, los sistemas procesales ameritan un importante replanteo, particularmente en tanto definen cómo se conforman subjetivamente los debates. Para cumplir cabalmente con la impronta participativa de los textos constitucionales en materia ambiental, el derecho procesal necesitará reforzar sus propias capacidades institucionales para obtener sentencias precedidas de robustas instancias de participación. 


\section{Bibliografía}

ALEXY, Robert, Teoría de los derechos fundamentales. Madrid: Centro de Estudios Políticos y Constitucionales, primera edición, 1997.

, "Ponderación, control de constitucionalidad y representación" en: Andrés Ibáñez y ALEXY, Jueces y ponderación argumentativa, Instituto de Investigaciones Jurídicas de la Universidad Nacional Autónoma de México, Ciudad de México, 2006

AUYERO, Javier y SWISTUM, Débora A., INFLAMABLE: estudio del sufrimiento ambiental. Buenos Aires, Editorial Paidós, primera edición, 2008.

BOURDIEU, Pierre, Poder, derecho y clases sociales, Bilbao, segunda edición, Editorial Desclée de Brouwer, 2001.

BRAÑES, Raúl, Informe sobre el desarrollo del derecho ambiental latinoamericano. Su aplicación después de diez años de la Conferencia de las Naciones Unidas sobre el Medio Ambiente y el Desarrollo. Ciudad de México, Programa de las Naciones Unidas para el Medio Ambiente (PNUMA), 2001.

CEPAL (Comisión Económica para América Latina y el Caribe), FAO (Organización de las Naciones Unidas para la Agricultura y la Alimentación) e IICA (Instituto Interamericano de Cooperación para la Agricultura), Perspectivas de la agricultura y del desarrollo rural en las Américas: una mirada hacia América Latina y el Caribe 20152016, San José, CEPAL, FAO e IICA, 2015.

CEPAL (Comisión Económica para América Latina y el Caribe), Perspectivas económicas de América Latina 2014. Logística y competitividad para el desarrollo, San José, CEPAL, 2014.

Los pueblos indígenas en América Latina. Avances en el último decenio y retos pendientes para la garantía de sus derechos, Santiago de Chile, CEPAL, 2014.

ENTELMAN, Remo F., Teoría de conflictos. Hacia un nuevo paradigma, Barcelona, Gedisa, primera reimpresión, 2005.

FAO (Organización de las Naciones Unidas para la Agricultura y la Alimentación), El estado de los bosques del mundo 2016. Los bosques y la agricultura: desafíos y oportunidades en relación con el uso de la tierra, Roma, FAO, 2016.

,Sitio web AQUASTAT (http://www.fao.org/nr/water/aquastat/ main/indexesp.stm) Accedido el 06/03/2017. 
FOUCAULT, Michel, Las palabras y las cosas, Buenos Aires, Siglo XXI, 1968.

, La verdad y las formas jurídicas, Barcelona, Gedisa, 1981.

GUDYNAS, Eduardo, Ecología, Economía y Ética del Desarrollo Sostenible, Montevideo, Coscoroba ediciones (CLAES-D3E), 2004.

"Agropecuaria y nuevo extractivismo bajo los gobiernos progresistas de América del Sur". En Revista Territorios, n 5, pp. 37-54. Guatemala: Instituto de Estudios Agrarios y Rurales - CONGCOOP, 2010.

,Derechos de la naturaleza. Ética biocéntrica y políticas ambientales. Buenos Aires, Tinta Limón, primera edición, 2015.

LASALLE, Ferdinand, ¿Qué es una constitución?, editado por elaleph.com, 1999.

PASTORINO, Leonardo Fabio, El daño al ambiente. Buenos Aires: Lexis Nexis Argentina, primera edición, 2005.

PÉREZ-RINCÓN, Mario Alejandro, “Conflictos ambientales en Colombia: inventario, caracterización y análisis". En Garay Salamanca [dir.], Minería en Colombia: Control público, memoria y justicia socio-ecológica, movimientos sociales y posconflicto. Bogotá: Contraloría General de la República, 2014.

SANTOS, Boaventura de Sousa, Refundación del Estado en América Latina. Perspectivas desde una epistemología del sur. Lima: Instituto Internacional de Derecho y Sociedad, 2010.

PNUMA (Programa de las Naciones Unidas para el Medio Ambiente), Perspectivas del medio ambiente: América Latina y el Caribe. Panamá: PNUMA, 2010.

REY SANTOS, Orlando, “El desarrollo del constitucionalismo ambiental en América Latina". En Quinto Programa Regional de Capacitación y Políticas Ambientales, pp. 385-399. Ciudad de Panamá: Programa de las Naciones Unidas para el Medio Ambiente (PNUMA), 2010.

SVAMPA, Maristella y VIALE, Enrique, Maldesarrollo. La Argentina del extractivismo y el despojo. Buenos Aires: Katz Editores, 2014.

TARUFFO, Michele, La prueba de los hechos. Madrid: Trotta, segunda edición, 2005.

, "Algunas consideraciones sobre la relación entre prueba y verdad". En La Prueba, Artículos y Conferencias. Santiago de Chile: Editorial Metropolitana, 2009. 
UPRIMNY Y., Rodrigo, “Las transformaciones constitucionales recientes en América Latina: tendencias y desafíos", en C. Rodríguez Garavito (coord.), El derecho en América Latina: un mapa para el pensamiento jurídico del siglo XXI. Buenos Aires: Siglo Veintiuno Editores, 2011.

YRIGOYEN FAJARDO, Raquel Z., “El horizonte del constitucionalismo pluralista: del multiculturalismo a la descolonización". En C. Rodríguez Garavito (coord.), El derecho en América Latina: un mapa para el pensamiento jurídico del siglo XXI. Buenos Aires: Siglo Veintiuno Editores, 2011. 